\title{
QUALIDADE DE AMBIENTES DE CRECHES: UMA ESCALA DE AVALIAÇÃO
}

\author{
Tatiana Noronha de Souza* \\ Mara Campos-de-Carvalho*
}

\begin{abstract}
RESUMO. Este estudo apresenta a análise de conteúdo da Infant/Toddler Environment Rating Scale-ITERS. Duas especialistas brasileiras em educação infantil analisaram a pertinência de cada um dos 35 itens da ITERS para avaliar a qualidade de ambientes educacionais oferecidos para crianças de 0 a 30 meses. Considerando-se os 70 itens avaliados, verificou-se que em 69 houve indicação de permanência e apenas uma sugestão de exclusão. As indicações de permanência dos itens foram classificadas nas seguintes categorias: Permanência sem sugestões de alterações (56\%); Permanência com sugestão de adequação de termos, de materiais ou de situações (19\%); Permanência com sugestão de acréscimo de esclarecimentos (11\%); Permanência com alterações de estrutura ou de conteúdo (10\%). O alto índice de acordo obtido entre as juízas (97\%) quanto à permanência de 34 itens sugere a pertinência da ITERS, representada pelos 35 itens, para avaliar a qualidade do atendimento oferecido em ambientes educacionais coletivos em nosso contexto.
\end{abstract}

Palavras-chave: escala de avaliação, qualidade, creche.

\section{QUALITY OF DAY CARE CENTER ENVIRONMENT: A RATING SCALE}

\begin{abstract}
This study presents an analysis of content of the Infant / Toddler Environment Rating Scale - ITERS. Two Brazilian experts in child education analyzed the pertinence of each of the 35 items of the ITERS to assess the quality of educational environments offered to children $0-30$ months years old. Considering the 70 items assessed, it was verified that in 69 of them there was indication of permanency, and only one suggestion of exclusion. The indications of permanency of the items were thus classified: permanency without suggestions of alterations $(56 \%)$; permanency with suggestion of adaptation of terms, materials or situations (19\%); permanency with suggestion of adding clarifications $(11 \%)$; permanency with structural or content alterations $(10 \%)$. The high index of agreement obtained between the two experts $(97 \%)$ as to the permanency of 34 items, suggests the pertinence of the ITERS, represented by the 35 items, to assess the quality of care offered in collective educational environments in our context.
\end{abstract}

Key words: assessment scale, quality, day-care center.

Acompanhando uma tendência internacional, constatamos, nos últimos trinta anos, uma expansão, no Brasil, da rede de atendimento às crianças de 0 a 6 anos em creches e pré-escolas. Várias são as causas desta expansão, dentre elas: (1) aumento da participação das mulheres no trabalho fora do lar; (2) modificação na organização e na estrutura familiar; (3) avanços no conhecimento científico sobre desenvolvimento e educação infantil (Oliveira, Mello, Vitória \& Rossetti Ferreira, 1995).

Além dessas causas, a Constituição de 1988 (Brasil, 1988), ao incluir a educação infantil no sistema educativo, passa a legitimá-la como direito da criança, dever do Estado e opção da família, além de contribuir para superar o caráter assistencialista predominante até aquele momento. Posteriormente, o Estatuto da Criança e do Adolescente-ECA (Brasil, 1990) reforçou os dispositivos constitucionais sobre a educação de zero a seis anos, impulsionando principalmente o crescimento de creches mantidas pelo poder público.

Com a Lei de Diretrizes e Bases da Educação Nacional-LDB (Brasil, 1996), a educação infantil foi colocada como a primeira etapa da educação básica.

\footnotetext{
* Doutoranda do Programa de Pós-Graduação em Psicologia da Faculdade de Filosofia, Ciências e Letras de Ribeirão PretoUniversidade de São Paulo.

** Doutora, Docente do Departamento de Psicologia e Educação da Faculdade de Filosofia, Ciências e Letras de Ribeirão PretoUniversidade de São Paulo.
} 
Define a lei que o atendimento de 0-3 anos será feito em creches e de 4-6 anos, em pré-escolas. A LDB explicita também que cabe a cada Conselho Municipal de Educação definir regulamentações para o funcionamento das instituições de educação infantil (com base em referenciais nacionais), ficando a cargo das secretarias municipais de educação tanto a autorização como a supervisão das instituições.

Nos últimos anos, o Ministério da Educação tem oferecido publicações para auxiliar na fase de transição das creches para o âmbito educacional (antes vinculadas às Secretarias de Bem-Estar Social). Tais publicações apontam diretrizes para a construção de uma regulamentação da educação infantil e também contribuem para a melhoria da qualidade do atendimento: (1) Referencial Curricular Nacional para a Educação Infantil (Ministério da Educação e do Desporto, 1998a); (2) Subsídios para Credenciamento e Funcionamento de Instituições de Educação Infantil (Ministério da Educação e do Desporto, 1998b); (3) Diretrizes Curriculares Nacionais para a Educação Infantil, Resolução CEB No 1, de 7 de abril de 1999 (Brasil, 1999); (4) Critérios para um Atendimento em Creches que Respeite os Direitos Fundamentais da Criança (Campos \& Rosemberg, 1995).

Dentre as diversas metodologias utilizadas atualmente para a melhoria da qualidade das instituições de educação infantil, destacamos o uso de escalas de avaliação, que permitem uma avaliação pormenorizada dos ambientes infantis. A Early Childhood Environment Rating Scale-ECERS (Harms \& Clifford, 1980), desenvolvida nos Estados Unidos, tem sido utilizada internacionalmente para avaliar a qualidade do ambiente educacional para crianças de 0 a 6 anos. É composta de 37 itens, organizados em sete subescalas: Cuidados Pessoais, Materiais e Mobiliário para as Crianças, Experiências de Linguagem e Raciocínio, Atividades de Motricidade Global e Fina, Atividades Criativas, Desenvolvimento Social e Necessidades do Adulto.

No Brasil, no estudo de Furtado e Campos-deCarvalho (Oliveira, Furtado, Souza \& Campos-deCarvalho, 2003), a ECERS foi aplicada em 19 grupos de crianças de 4 a 6 anos, de pré-escolas de Ribeirão Preto (SP), com o objetivo de avaliar sua adequação ao nosso contexto, verificando sua precisão e iniciando o estudo da validade do instrumento. Utilizou-se a tradução da escala original feita pelo grupo de pesquisadores da Universidade do Porto Portugal (Bairrão, 1997), sendo alguns termos modificados, por serem mais apropriados a nossa cultura. A verificação da precisão do instrumento foi realizada por dois avaliadores independentes, em nove aplicações da escala em salas de instituições privadas, municipais e filantrópicas; $\mathrm{O}$ acordo obtido chegou a $88 \%$, indicando um bom índice de precisão da escala. Os 19 grupos apresentaram escores totais bem abaixo do escore máximo possível de ser obtido, porém, acima do escore mínimo possível de ser atribuído, indicando uma baixa qualidade do atendimento oferecido, especialmente nas instituições filantrópicas. A ECERS se mostrou sensível para discriminar instituições privadas, municipais e filantrópicas, para diferenciar as salas entre si pertencentes a um mesmo tipo de instituição, indicando aspectos satisfatórios e deficitários específicos a cada sala, fator essencial para a implantação de mudanças visando a melhorias na qualidade do atendimento oferecido.

Com base na ECERS, Harms, Cryer \& Clifford (1990) desenvolveram a Infant/Toddler Environment Rating Scale-ITERS, para avaliar especificamente a qualidade do ambiente oferecido para o atendimento coletivo de crianças de até 30 meses de idade. Esta escala é composta de 35 itens, agrupados em 7 subescalas: Material e Mobiliário, Rotinas e Cuidados Pessoais, Linguagem Oral e Compreensão, Atividades de Aprendizagem, Interação, Estrutura do Programa e Necessidades dos Adultos. Tanto a ITERS como a ECERS podem ser aplicadas em qualquer instituição educacional que ofereça cuidado infantil; o observador/avaliador pode ser interno ou externo ao grupo, com alguma prática no trabalho direto com crianças, observando, por vez, um grupo de crianças e sua(s) educadora(s) durante um período de duas horas ou mais. Alguns itens (por exemplo, saúde, segurança e necessidades do adulto) necessitam informação adicional, além da observação, a qual pode ser obtida com a educadora.

Oliveira (Oliveira, Furtado, Souza \& Camposde-Carvalho, 2003) desenvolveu um estudo preliminar com a ITERS, a qual foi aplicada em quatro turmas de creches filantrópicas e em seis turmas de creches municipais, da cidade de Ribeirão Preto (SP). Inicialmente, foi realizada uma tradução da ITERS para a língua portuguesa, com adequação de alguns termos para o contexto cultural e social brasileiro (por exemplo, relacionados ao clima, materiais e equipamentos). $\mathrm{Na}$ etapa de análise da precisão do instrumento, dois observadores aplicaram independentemente a escala traduzida em quatro turmas de creches filantrópicas e em seis municipais - obteve-se o índice de $82 \%$ de acordo entre os avaliadores nas instituições públicas e de 83\% nas instituições filantrópicas, indicando a precisão da escala. 
Dando continuidade à verificação da adequabilidade da ITERS em nosso contexto, iniciado por Oliveira (2000), Souza realizou um estudo em creches de Ribeirão Preto (SP), para analisar parâmetros psicométricos da ITERS, tais como sua precisão e sensibilidade para discriminar diferentes tipos de creche e dar início a uma análise do conteúdo dos itens da escala (Souza, 2003). Este estudo englobou três etapas, sendo que na Etapa I familiarização e treinamento da aplicadora com o instrumento - a ITERS foi aplicada em sete turmas de creches filantrópicas. Em duas delas foi realizado um teste de acordo com os escores atribuídos por duas avaliadoras independentes, para decidir o término desta etapa. Dada a obtenção de um bom índice de acordo (88\%), encerrou-se então esta etapa. Na Etapa II foram avaliados os seguintes aspectos dos itens da escala: (1) análise do conteúdo - examinaram-se os pareceres de duas especialistas brasileiras em educação infantil, em relação à pertinência de cada item da escala em avaliar os atributos ambientais propostos; (2) sensibilidade da escala para diferenciar os três modelos de creche utilizados no estudo (sete turmas filantrópicas, 22 municipais e três turmas da creche do Campus da Universidade de São Paulo em Ribeirão Preto). Na Etapa III, foi realizada a verificação da precisão do instrumento, utilizando-se um teste de acordo entre duas avaliadoras independentes na aplicação da escala em quatro turmas de creches municipais.

Os dados obtidos nas Etapas I e III e parte dos dados obtidos na Etapa II (referentes à sensibilidade da escala em discriminar os três tipos de creches), foram analisados em conjunto com as aplicações feitas no estudo de Oliveira (2000), totalizando 42 turmas avaliadas, evidenciando-se (Oliveira, Furtado, Souza \& Campos-de-Carvalho, 2003): (1) um nível satisfatório de precisão da ITERS, dado que o índice de acordo entre dois avaliadores independentes foi acima de 85\%; (2) baixo nível de qualidade do atendimento nas redes filantrópica e municipal, nesta havendo melhor qualidade; (3) alto nível de qualidade na creche universitária; (4) a sensibilidade da ITERS para discriminar (a) os três modelos de instituições (filantrópica, municipal e universitária), (b) diferenças entre turmas, considerando cada modelo de creche e (c) diferenças dentro da mesma turma, sendo este aspecto relevante para o planejamento de melhoria no atendimento.

O presente artigo objetiva apresentar os dados obtidos no estudo de Souza (2003), referentes à análise do conteúdo dos itens da ITERS realizada com os pareceres de duas especialistas em educação infantil. A análise do conteúdo de itens, um dos parâmetros psicométricos de um instrumento, é realizada por peritos na área em questão, pois visa a estabelecer a pertinência dos itens ao atributo que pretendem medir - uma "concordância de, pelo menos, $80 \%$ entre os juízes pode servir de critério de decisão sobre a pertinência do item ao traço a que teoricamente se refere" (Pasquali, 1996, p. 82). Ademais, apresentamos no presente artigo uma discussão sobre os desacordos ocorridos durante a verificação da precisão da ITERS. Tanto esta discussão como a análise de conteúdo, não inclusas no artigo anterior (Oliveira, Furtado, Souza \& Camposde-Carvalho, 2003), fornecem subsídios para auxiliar numa discussão, que se faz necessária, sobre a necessidade de adaptação de alguns itens da ITERS ao nosso contexto sociocultural.

\section{MÉTODO}

As secções aqui descritas são relativas à análise de conteúdo dos itens da ITERS (para uma descrição completa do método utilizado no estudo de Souza, vide Souza, 2003).

\section{Material}

No estudo de Souza (2003), a ITERS foi aplicada em 32 turmas de creches de Ribeirão Preto (SP), sete da rede filantrópica, 22 turmas da rede municipal e três da creche universitária do Campus da USP de Ribeirão Preto. Utilizou-se a versão provisória da Infant Toddler Environment Rating Scale -ITERS (Harms, Cryer \& Clifford, 1990), realizada no estudo de Oliveira (2000), sendo denominada de Escala de Avaliação de Ambientes para Crianças de 0-30 meses (mantivemos o uso da sigla em língua inglesa, ITERS).

A ITERS é composta por 35 itens, agrupados em sete subescalas, descritos resumidamente a seguir.

- Subescala I. Rotinas/cuidados pessoais: abrange todas as rotinas associadas ao conforto, saúde e bem-estar das crianças, abrangendo nove itens: 1 . Organização da chegada/saída; 2. Refeições/merendas; 3. Sono; 4. Condições de higiene; 5. Cuidados pessoais; 6. Práticas de condições de saúde; 7. Regulamentação das condições de saúde; 8. Práticas de condições de segurança; 9. Regulamentação das condições de segurança.

- Subescala II. Material/mobiliário para as crianças: refere-se à forma de organização, de manutenção e de uso do espaço, do material e do mobliliário, abrangendo cinco itens: 10. Mobiliário para 
cuidados de rotina; 11. Mobiliário para atividades de aprendizagem; 12. Mobiliário para relaxamento e conforto; 13. Arranjo da sala; 14. Exposição de materiais.

- Subescala III. Linguagem oral e compreensão: refere-se à forma como a educadora enfatiza a comunicação oral e ao uso de materiais que promovem a linguagem, abrangendo dois itens: 15 . Uso informal da linguagem; 16. Livros e figuras.

- Subescala IV. Atividades de aprendizagem: atividades que exercitam a motricidade fina e global, incluindo também atividades de música, arte e faz-deconta, abrangendo oito itens: 17. Coordenação visomotora; 18. Atividade física; 19. Arte; 20. Música e movimento; 21. Blocos/materiais de construção; 22. Faz-de-conta; 23. Areia/água; 24. Perspectiva multicultural.

- Subescala V. Interação: refere-se à forma como ocorre a interação adulto-criança e como a educadora promove a interação entre crianças, abrangendo três itens: 25. Interação criançacriança; 26. Interação adulto-criança; 27. Disciplina.

- Subescala VI. Estrutura do programa: refere-se ao planejamento e supervisão das atividades de aprendizagem, abrangendo quatro itens: 32 . Programa de atividades diárias; 33. Supervisão de atividades diárias; 34. Cooperação entre a equipe; 35. Adequação para crianças com necessidades específicas.

- Subescala VII. Necessidades do adulto: abrange a presença de espaços e equipamentos para os adultos (pais e educadores) e atendimento de suas necessidades, compreendendo quatro itens: 28. Necessidades pessoais do adulto; 29. Oportunidades para crescimento profissional; 30. Área de encontro de adultos; 31. Medidas para envolvimento dos pais.

As descrições contidas em cada item da escala direcionam as observações realizadas junto ao grupo de crianças que está sendo avaliado, possibilitando a escolha do escore a ser atribuído em uma escala de 1 a 7, indicativa da qualidade do atendimento oferecido: (1) inadequado, (3) mínimo, (5) bom e (7) excelente. Qualquer um destes quatro escores só pode ser atribuído quando todas as condições descritas naquele escore estiverem presentes, com exceção da pontuação 1, a qual é atribuída se qualquer parte da descrição se aplica à situação observada. As pontuações intermediárias - 2, 4 e 6 - são utilizadas quando estão presentes todas as condições da pontuação inferior e pelo menos a metade das condições da pontuação superior. Em geral, a decisão do escore a ser atribuído para cada item da escala é tomada simultaneamente à observação do grupo, sendo então circulada a pontuação referente no protocolo de registro (proposto na escala original). A critério do observador, anotações da situação observada referentes àquele item podem ser feitas no protocolo; ademais, para alguns itens, previstos na escala, também há a necessidade de esclarecimentos com a equipe.

\section{Procedimento de coleta e análise de dados}

Cópias da escala traduzida foram enviadas a duas psicólogas, especialistas em educação infantil, com ampla experiência tanto de atuação profissional em creches como de pesquisa e supervisão de estagiários e profissionais de creches. Solicitou-se o parecer de cada uma delas sobre os itens abrangidos pela escala, em relação à sua pertinência para avaliar a qualidade de ambientes educacionais coletivos oferecidos para crianças de 0 a 30 meses.

Primeiramente, o parecer de cada juíza foi classificado em relação à indicação de exclusão ou permanência de cada item na escala. No caso de indicação de permanência do item na escala, foram identificadas, após leitura cuidadosa dos pareceres, cinco possíveis categorias de análise, excludentes entre si: (1) permanência do item sem sugestão de alterações; (2) permanência do item com sugestão de adequação de termos, de materiais ou de situações; (3) permanência do item com sugestão de acréscimo de esclarecimentos (o recurso de notas de esclarecimento é muito utilizado na escala original, colocado ao lado do item que está sendo descrito, sendo sempre precedido, na descrição da pontuação daquele item, por um símbolo); (4) permanência do item com alterações de estrutura ou de conteúdo; (5) permanência do item com sugestão não compreensiva (o comentário não foi claro o suficiente para permitir sua categorização). Verificou-se a ocorrência de acordos e desacordos entre as juízas quanto à indicação de exclusão ou permanência de itens e de sugestões de alterações nos itens da ITERS, levando em conta essas cinco categorias de análise.

Em seguida, os acordos observados quanto à permanência de cada item foram classificados em quatro outras categorias: (1) sem alteração - nãoindicação de alterações na descrição do item; (2) com alteração (mesma categoria) - as alterações indicadas por ambas as juízas foram classificadas na mesma categoria, considerando as três categorias de sugestões de alteração da análise anterior (alteração de estrutura ou conteúdo; adequação de termos/materiais/situações; 
inclusão de esclarecimentos por dificuldade de compreensão); (3) com alteração (categorias diferentes ) - as alterações indicadas pelas juízas foram classificadas em categorias diferentes; (4) divergência na necessidade de alteração - ocorrência de divergência entre as especialistas quanto à necessidade de alteração do item.

\section{RESULTADOS/DISCUSSÃO}

Esta secção está subdividida em duas partes: (1) Análise do conteúdo dos itens; (2) Análise dos desacordos ocorridos quanto à atribuição de escores por dois aplicadores independentes.

\section{Análise do conteúdo dos itens}

Considerando-se o conjunto de 70 itens avaliados pelas especialistas (35 itens para cada juíza), em 69 (99\%) houve indicação de permanência e apenas uma sugestão de exclusão, referente ao item 21-Blocos/Material de Construção. Quanto à permanência dos itens, observou-se a seguinte distribuição pelas cinco categorias de análise: $56 \%$ (39) dos itens foram classificados na categoria Permanência do item sem sugestão de alterações; $19 \%$ (13) foram classificados na categoria Permanência do item com sugestão de adequação de termos, de materiais ou de situações; $11 \%$ (8) foram classificados na categoria Permanência do item com sugestão de acréscimo de esclarecimentos; $10 \%$ (7) na categoria Permanência do item com alterações de estrutura ou de conteúdo. A categoria Permanência do item com sugestão não compreensiva ocorreu duas vezes $(3 \%)$, referindo-se apenas a uma das especialistas.
A classificação inicial nestas cinco categorias permitiu a verificação dos acordos e desacordos entre as juízas quanto à pertinência ou não de cada item para medir o que a escala se propõe. A freqüência de acordos observada sobre a permanência do item, reagrupados em quatro categorias, está mostrada na Tabela 1, assim como a freqüência de desacordos sobre a permanência do item. Em relação à indicação de permanência ou exclusão do item na escala, em 34 itens $(97 \%)$ as duas especialistas concordaram com sua permanência e em apenas um (item 21Blocos/Materiais de Construção, da subescala IVAtividades de Aprendizagem) houve desacordo, pois a Juíza 2 indicou exclusão e a Juíza 1, permanência sem nenhuma sugestão de alteração. Considerando o índice mínimo de $80 \%$ de acordo, apontado por Pasquali (1996) como critério de decisão sobre a pertinência, o alto índice de acordo obtido entre as juízas (97\%) quanto à permanência de 34 itens sugere a pertinência da ITERS, representada pelos 35 itens e suas descrições, para avaliar o que a escala se propõe qualidade do atendimento oferecido em ambientes educacionais coletivos em nosso contexto.

Em 15 dos 35 itens (43\%) houve convergência entre os pareceres das duas juízas, sendo que em 13 deles (vide Tabela 1), ambas sugeriram a nãoindicação de alterações na descrição do item. Em dois itens, 11 e 18, as duas especialistas sugeriram alterações que, embora classificadas na mesma categoria (Permanência do item com sugestão de adequação de termos, de materiais ou de situações) não são idênticas: no item 11 (Práticas das condições de saúde), da subescala II-Rotina/Cuidados Pessoais, a Juíza 1 sugere a inclusão de doenças infectocontagiosas nas descrições do item; já a Juíza 2 sugere acrescentar que, para os três estados do Sul do Brasil,

Tabela 1. Freqüência de Acordos e Desacordos entre Duas Juízas Brasileiras Quanto à Pertinência dos Itens da ITERS, Distribuídos pelas Categorias de Análise

\begin{tabular}{|c|c|c|c|c|c|c|c|c|c|c|c|}
\hline \multirow[t]{3}{*}{ Sub-escala } & \multicolumn{8}{|c|}{ Acordo sobre permanência } & \multicolumn{2}{|c|}{$\begin{array}{c}\text { Desacordo sobre } \\
\text { permanência }\end{array}$} & \multirow[t]{3}{*}{$\begin{array}{c}\text { Total de } \\
\text { itens } \\
\end{array}$} \\
\hline & \multicolumn{2}{|c|}{ Sem alteração } & \multicolumn{2}{|c|}{$\begin{array}{c}\text { Com alteração } \\
\text { (mesma categoria) }\end{array}$} & \multicolumn{2}{|c|}{$\begin{array}{c}\text { Com alteração } \\
\text { (categorias diferentes) }\end{array}$} & \multicolumn{2}{|c|}{$\begin{array}{c}\text { Divergência na } \\
\text { necessidade de } \\
\text { alteração }\end{array}$} & \multirow{2}{*}{\multicolumn{2}{|c|}{ (item) }} & \\
\hline & $\mathbf{N}$ & (item) & $\mathbf{N}$ & (item) & $\mathbf{N}$ & (item) & $\mathbf{N}$ & (item) & & & \\
\hline I & 3 & $(3-4-5)$ & & & 1 & (2) & 1 & (1) & & - & 5 \\
\hline II & 22 & $(8-12)$ & 11 & (11) & 2 & $(9-14)$ & 4 & $(6-7-10-13)$ & & - & 9 \\
\hline III & & - & & - & 1 & (16) & 1 & (15) & & - & 2 \\
\hline IV & & - & 11 & (18) & 3 & $(17-19-20)$ & 3 & $(22-23-24)$ & 1 & (21) & 8 \\
\hline V & 33 & $(25-26-27)$ & & - & & - & & - & & - & 3 \\
\hline VI & 22 & $(29-31)$ & & - & & - & 2 & $(28-30)$ & & - & 4 \\
\hline VII & 33 & $(32-34-35)$ & & - & & - & 1 & (33) & & - & 4 \\
\hline Total & & 13 & & 02 & & 07 & & 12 & & 01 & 35 \\
\hline
\end{tabular}


devido ao clima, a limpeza do tanque de areia seja quinzenal, não havendo necessidade de mantê-lo coberto, como proposto na escala. No item 18 (Atividade Física), da subescala IV-Atividades de Aprendizagem, as duas especialistas sugeriram aspectos diferentes, classificados na categoria de alterações de estrutura/conteúdo (a escala aponta, nas descrições do escore 5 , que bebês e crianças pequenas devem ficar separados das maiores - a Juíza 1 sugere que, dependendo da proporção adulto-criança, é interessante que, em alguns momentos, as crianças pequenas fiquem com as maiores. Já a Juíza 2 sugere a inserção de um único item - denominado de Linguagem Gestual e Movimento - unindo o item 18 ao item 17 sobre Coordenação visomotora).

Em 7 itens (20\%), as duas juízas concordaram com a sua permanência, mas sugeriram alterações classificadas em categorias diferentes (sugestão para adequação de termos ou situações, para inclusão de esclarecimentos e alteração de estrutura ou conteúdo dos itens).

Em 12 itens (34\%), mostrados na Tabela 1, houve acordo entre as duas juízas em relação à permanência dos mesmos, mas com divergência quanto à necessidade de alterações, pois apenas uma delas sugere alterações. Em 8 itens, apenas a Juíza 1 sugeriu alterações: item 1 (Mobiliário para Cuidados de Rotina), da subescala I - Material e Mobiliário para as Crianças, itens 6 (Chegada e Saída), 10 (Cuidados Pessoais) e 13 (Práticas de Condições de Segurança), da subescala II - Rotina/Cuidados Pessoais; item 24 (Perspectiva Multicultural), da subescala IV Atividades de Aprendizagem; itens 28 (Programa de Atividades Diárias) e 30 (Cooperação entre a Equipe), da subescala VI - Estrutura do Programa; item 33 (Oportunidade de Desenvolvimento Profissional), da subescala VII - Necessidades do Adulto. Em 4 itens, apenas a Juíza 2 sugeriu alterações: item 7 (Refeições e Merendas), da subescala II - Rotiana/Cuidados Pessoais; 15 (Uso Informal da Linguagem), da subescala III - Linguagem Oral e Compreensão; itens 22 (Faz de Conta) e 23 (Areia/Água), pertencentes à subescala IV - Atividades de Aprendizagem.

Em relação às subescalas, considerando-se os pareceres das duas especialistas em conjunto, destacou-se a V - Interação (vide Tabela 1), que obteve, em seus três itens, acordo total entre as juízas; ou seja, não recebeu nenhuma sugestão de alteração, indicando uma maior suficiência, em comparação às demais subescalas, para a avaliação de ambientes infantis em nosso contexto. Por outro lado, considerando-se as 21 sugestões de alteração (nove delas presentes nos pareceres de ambas as especialistas e 12 no parecer de uma só), as subescalas
II (Rotina/Cuidados Pessoais), III (Linguagem Oral e Compreensão) e IV (Atividades de Aprendizagem) destacaram-se pelo maior número de alterações sugeridas por ambas as juízas (sejam classificadas na mesma ou em categorias diferentes), considerando a quantidade de itens que compõem cada subescala (um item em dois da subescala III/quatro em 8 itens para a IV/três em nove itens da II).

A subescala III obteve sugestão de alteração nos dois itens que a compõem - inclusão de revistas e gibis nos materiais indicados e de mudança do nome da subescala (para Linguagem Oral e Dramática). Em relação às subescalas II e IV, levantamos duas questões sobre o conteúdo descrito nos seus itens: (1) seriam as descrições contidas não compatíveis com as concepções a respeito da rotina de cuidado (subescala II) e atividades de aprendizagem (subescala IV) dos educadores das creches avaliadas? (2) Desde que as descrições contidas nas duas subescalas têm como norteador um padrão de qualidade excelente (escore 7 de cada item), será que a maioria das salas avaliadas não alcançou um bom padrão de qualidade nessas subescalas por motivos financeiros apenas e/ou culturais?

De qualquer modo, é importante aprofundar a análise dos itens da ITERS com um maior número de profissionais da área, para que se possa decidir sobre a pertinência de seus itens para o nosso contexto. É também necessária uma análise semântica (Pasquali, 1996), relativa à clareza ou compreensão pelo avaliador quanto à linguagem utilizada nas descrições apresentadas para cada escore nos itens componentes da ITERS - ou seja, se a sentença escrita expressa claramente o que deverá ser observado no grupo avaliado, para a tomada de decisão quanto à atribuição do escore àquele item.

Embora a solicitação às juízas tenha sido feita em relação à pertinência dos itens relativos à avaliação de ambientes infantis coletivos, uma delas contribuiu espontaneamente com informações relativas a uma análise semântica, quanto à dificuldade na compreensão de seis itens $(1,2,6,28,30$ e 33). Nestes itens, a juíza sugere a inserção de esclarecimentos para aumentar a clareza na descrição das condições a serem observadas (por exemplo, para esclarecer de que maneira as relações interpessoais no trabalho podem interferir nas responsabilidades da educadora com as crianças, como apontado no item 30 - Cooperação entre a equipe). Como as instruções fornecidas às especialistas não incluíam uma análise semântica, não podemos afirmar que os itens nos quais este aspecto não foi apontado estejam, para as especialistas, suficientemente claros e compreensíveis tal como 
apresentados na descrição da escala. Apesar disso, o presente estudo fornece uma indicação da dificuldade de compreensão destes seis itens e sobre a necessidade de se realizar uma análise semântica dos itens da ITERS, a qual deverá ser realizada em próximos estudos.

Em resumo, o alto índice de acordo entre as juízas (97\%) quanto à permanência de 34 itens sugere a pertinência da ITERS para medir aquilo a que se propõe, ou seja, a qualidade do atendimento oferecido em nossas creches. A maior parte das sugestões de alterações indicadas (43\%) nos itens que compõem a ITERS, relativas às quatro categorias de alterações, não são contrárias às descrições relativas às práticas contidas na escala, mas dizem respeito a adequações ao nosso contexto (especialmente quanto a termos e materiais) e esclarecimentos para o usuário da escala. Porém, há necessidade de estudos futuros envolvendo o parecer de um maior número de especialistas em educação infantil, com o propósito de inserir modificações na ITERS, tanto referentes às sugestões de alteração de estrutura ou conteúdo como às demais sugestões apresentadas. Além disso, esses estudos deverão contemplar um número ímpar de juízes, necessário do ponto de vista de desempate nos resultados.

\section{Análise dos desacordos entre dois aplicadores independentes}

A fim de complementar uma reflexão sobre a descrição de itens da ITERS, apresentamos aqui possíveis explicações para a ocorrência dos desacordos ocorridos entre dois avaliadores independentes, análise feita no estudo de Souza (2003) para verificar a precisão da ITERS em nosso contexto. No total de 196 itens avaliados (em seis turmas avaliadas, nas quais houve a exclusão, durante a aplicação, de 14 itens, segundo indicação da escala original), obteve-se o índice de $92 \%$ de acordo (180 itens) nas pontuações dadas pelas duas aplicadoras, o que indica um alto índice de fidedignidade da escala, levando-se em conta que um índice igual ou superior a $70 \%$ é tido como satisfatório (Weick, 1968; Weiner, 1991).

Os 16 desacordos $(8 \%)$ na pontuação atribuída pelas duas avaliadoras ocorreram nos seguintes itens: itens 1 (Mobiliário para Cuidados de Rotina subescala I) e 6 (Chegada/Saída - subescala II), nos quais houve maior ocorrência de desacordos (em três das seis turmas); itens 15 (Uso Informal da Linguagem - subescala III) e 23 (Areia/Água - subescala IV), havendo, respectivamente, desacordos em duas turmas avaliadas. Os desacordos nos demais itens $(2,5,8,20$, 30 e 32) ocorreram em apenas uma turma.

Todos estes 10 itens com desacordos envolveram uma pontuação intermediária (em nove deles, o escore 2 e em 1, o escore 4). Em oito deles havia um número ímpar de condições na pontuação superior, fato este que dificulta a tomada de decisão pelo avaliador, devido ao critério da ITERS para atribuição de pontuação intermediária - além de todas as condições da pontuação inferior, é necessária a presença de pelo menos a metade das condições da pontuação superior (como decidir a metade em relação ao número ímpar de condições?).

Para verificar esta nossa hipótese (dificuldade na decisão de pontuação intermediária na presença de número ímpar de condições), fez-se necessário examinar a ocorrência dos acordos entre as duas aplicadoras, considerando-se as seisturmasdiscriminando-se os acordos que envolviam escores intermediários. Verificamos uma freqüência de 10 acordos envolvendo escores intermediários, distribuídos por oito itens $(3,5,6,9,10,13,18,32$ nos itens 5 e 18 estava envolvido o escore 4 e nos demais, o escore 2). Embora afreqüência de acordos (10) seja menor que a de desacordos (16), todos eles envolvendo um escore intermediário, como já apontado, a ocorrência de acordos entre as duas aplicadoras em seis dos oito itens envolvendo um número ímpar de condições na pontuação superior não favorece completamente aquela nossa hipótese. Entretanto, parece-nos significativo o fato de que todos os desacordos observados ocorreram quando estavam envolvidos escores intermediários, sendo que na maioria deles havia um número ímpar de condições na pontuação superior.

Além da dificuldade de se atribuir uma pontuação intermediária quando $\mathrm{o}$ escore superior possui condições ímpares, em relação ao item 6 foi levantada outra questão que pode ter contribuído para os desacordos: observação em situações dinâmicas. Por exemplo, na chegada e saída de pais, é comum a presença de vários pais ao mesmo tempo, o que possibilita a observação de diferentes aspectos, da mesma situação, por parte dos aplicadores.

Itens contendo descrições com termos imprecisos e/ou observação de situações dinâmicas possibilitam que significados ou concepções pessoais exerçam influência na análise destas situações e, conseqüentemente, na atribuição dos escores. Novamente, uma análise semântica dos itens, a ser realizada, poderá embasar estes nossos comentários.

$\mathrm{Na}$ maioria das descrições com termos imprecisos, é possível inserir uma quantificação na descrição, para 
facilitar a observação e avaliação do item. Por exemplo, na descrição de materiais, substituir "alguns brinquedos estão disponíveis" por esclarecimento do tipo "no mínimo x de brinquedos"; em relação a "alguma atividade musical é feita", colocar o que se entende por alguma (pelo menos uma atividade por dia? por semana?); em relação à presença de uma "equipe para cobrir eventuais ausências ou intervalos não programados", inserir qual seria o número suficiente de profissionais.

Em itens onde há uma dificuldade maior para quantificação, podem-se inserir esclarecimentos que auxiliarão o observador. Por exemplo: na descrição "os deveres dos educadores são divididos de modo justo" (escore 3 do item 30-Cooperação entre a equipe, da subescala VI- Estrutura do Programa), a inserção de pelo menos um exemplo da não-divisão de deveres poderá auxiliar o observador (tal como: um educador dá banho e troca todas as crianças, enquanto o outro permanece sentado ou conversando com outro membro da equipe); na descrição "há algumas respostas (do adulto) às tentativas de comunicação das crianças" (escore 3 do item 15-Uso Informal de Linguagem, da subescala III- Linguagem Oral e Compreensão), pode-se esclarecer o que se entende por isso, através de pelo menos um exemplo (tal como: a educadora dá atenção e responde aos balbucios dos bebês).

Quanto ao item 23-Areia/Água (subescala IVAtividades de Aprendizagem), com dois desacordos relacionados à pontuação intermediária, foi questionado ainda o destaque dado pela ITERS à presença de tanque de areia na instituição. No caso da instituição universitária, que obteve altos índices de qualidade pela avaliação da ITERS, a frequiência do uso da areia é pequena diante da diversidade de atividades que os demais espaços externos proporcionam e que a instituição privilegia. Já nas instituições municipais, percebeu-se uma alta utilização do tanque de areia, em detrimento da presença de amplas áreas verdes, ocupadas apenas pelos equipamentos tradicionais de parquinhos $\mathrm{e}$ tanques de areia, não havendo outras propostas de atividades para as crianças. Nossa sugestão dirige-se para a inclusão de descrições a respeito do uso de espaços ao ar livre, para permitir o contato da criança com a natureza; é necessário também apontar que deve haver um equilíbrio na distribuição das atividades nestes espaços, para proporcionar um aumento na diversidade de experiências oferecidas às crianças, e não apenas a valorização do tanque de areia. $\mathrm{Na}$ atualidade, especialmente em grandes centros urbanos, tal planejamento se faz necessário, pois geralmente creches e pré-escolas oferecem uma das raras, senão a única oportunidade para o contato com a natureza; a paisagem, a vegetação e animais podem ser utilizados como materiais para brincadeiras e explorações livres, permitindo, tanto quanto as salas, a ocorrência de aprendizagem de uma série de conceitos e, muito mais que espaços internos, a estimulação de todos os sentidos e da curiosidade (White \& Stoecklin, 1998). Ademais, equipamentos tradicionais de parquinhos podem ser incorporados à paisagem (por ex., aproveitando o declive do terreno para aí encaixar um escorregador). Prescott (1987) resume em três aspectos as qualidades de ambientes ao ar livre: sua contínua diversidade, não terem sido construídos por pessoas e o sentimento de serem atemporais (sem começo e fim).

\section{CONCLUSÃO}

A análise de conteúdo dos itens da ITERS, apresentada no presente artigo, revelou (a) a pertinência dos mesmos em avaliar a qualidade do atendimento infantil, segundo os pareceres das duas especialistas em educação infantil, e (b) a necessidade de estudos posteriores a fim de validá-la para nosso contexto.

A ITERS baseia-se em uma definição ampla de ambiente (Harms, Cryer \& Clifford, 1990), incluindo desde a sua dimensão física e as inter-relações possíveis até a estrutura do programa e as necessidades da equipe. Desta maneira, seus 35 itens proporcionam uma visão geral da qualidade do atendimento coletivo oferecido para um grupo de crianças, ultrapassando os elementos estruturais e objetos/equipamentos disponíveis.

A ITERS é um recurso útil para a promoção de qualidade do atendimento oferecido em creches, tendo em vista seu uso como um instrumento de reflexão na formação de educadores e em projetos de intervenção, ao permitir a identificação de aspectos positivos já presentes e daqueles que necessitam ser melhorados. Uma discussão dos indicadores de qualidade descritos na ITERS com a equipe de funcionários pode favorecer o reconhecimento da importância destes indicadores, bem como o levantamento de outros descritores de qualidade importantes para o contexto de funcionamento daquela creche específica.

É relevante observar que vários aspectos apontados na análise inclusa no presente artigo foram incorporados numa recente revisão da escala - ITERSR (Harms, Cryer \& Clifford, 2003). Esta edição revisada incluiu mudanças essenciais para uma maior objetivação da atribuição dos escores, tais como 
especificação de termos imprecisos (alguns / periodicamente), bem como a inclusão de novos itens.

Apesar de a ITERS-R conter maior objetivação que sua versão anterior para decisão dos escores a serem atribuídos, é nossa opinião que qualquer metodologia de avaliação possui suas limitações. Não há um instrumento de avaliação, ou estratégia de intervenção, que abarque todos os aspectos relativos à qualidade; ademais, os valores e concepções do observador influenciam na suaavaliação. Embora toda avaliação de qualidade (e talvez de qualquer outra dimensão) envolva juízos de valor, com certeza quanto mais objetivas forem as descrições do instrumento utilizado e mais rigorosa for a formação do avaliador (prévia e continuada) sobre educação infantil, bem como seu treinamento específico no instrumento a ser utilizado, menores serão seus julgamentos subjetivos sobre os aspectos ambientais avaliados.

Atualmente, a ITERS $-R$ está sendo traduzida para a língua portuguesa, primeiro passo necessário para ser utilizada em próximos estudos. Em 2003, dois novos projetos foram planejados com a ITERS, nos quais, agora, usaremos a ITERS-R. Campos-deCarvalho (2003) está propondo a realização de um projeto inter-regional, que visa a dar continuidade aos estudos anteriores da adequabilidade da ITERS para o contexto sociocultural brasileiro, verificando a consistência da escala na avaliação de creches em diferentes regiões do Brasil. O segundo projeto está sendo desenvolvido por Souza (2003b), com o objetivo de analisar princípios de qualidade em documentos nacionais e estrangeiros. Esse trabalho emergiu ao longo da pesquisa aqui relatada, na qual se verificou, na literatura consultada, a existência de um compartilhamento de certos princípios de qualidade na educação infantil em documentos de diversos países ocidentais industrializados.

Estas pesquisas poderão colaborar, teórica e empiricamente, para o conhecimento sobre o padrão de qualidade em educação infantil em nosso contexto e contribuir para as discussões sobre princípios de qualidade no atendimento infantil. Tais princípios têm sido construídos pela comunidade educacional no Brasil e em outros países de cultura ocidental, sendo necessários para subsidiar programas de educação infantil.

\section{REFERÊNCIAS}

Bairrão, J. (1997). Escala de avaliação do ambiente de educação infantil. Versão provisória para investigação. Portugal: Universidade de Lisboa.
Brasil (1988). Constituição da República Federativa do Brasil. Brasília.

Brasil (1990). Estatuto da Criança e do Adolescente. Brasília.

Brasil (1996). Lei de Diretrizes e Bases da Educação Nacional. Brasília.

Brasil (1999). Diretrizes Curriculares Nacionais para a Educação Infantil. CEB - Câmara de Educação Básica do Conselho Nacional de Educação. Resolução No 1. Brasília.

Campos-de-Carvalho, M. I. (2003). Arranjos espaciais $e$ comportamentos de crianças pequenas em creches. Projeto de pesquisa submetido ao $\mathrm{CNPq}$ para solicitação de renovação de bolsa de produtividade em Pesquisa.

Campos, M. M. \& Rosemberg, F. (1995). Critérios para um atendimento em creches que respeite os direitos fundamentais da criança. Brasília: MEC /SEF /COEDI.

Harms, T. \& Clifford, R. M. (1980). Early Childhood Environment Rating Scale. New York: Teachers College Press.

Harms, T., Cryer, D. R. \& Clifford, R. M. (1990). Infant/Toddler Environment Rating Scale. New York: Teachers College Press.

Harms, T., Cryer, D. R. \& Clifford, R. M. (2003). Infant/Toddler Environment Rating Scale - Revised Edition. New York: Teachers College Press.

Ministério da Educação e do Desporto. (1998a). Referencial Curricular Nacional para a Educação Infantil. Brasília: Secretaria de Educação Fundamental.

Ministério da Educação e do Desporto. (1998b). Subsídios para Regulamentação e Credenciamento das Instituições Infantis. Vol I. Brasília: Secretaria de Educação Fundamental.

Oliveira, M. A. de (2000). Avaliação de ambientes coletivos para crianças pequenas. Monografia de Conclusão do Programa de Bacharelado do Departamento de Psicologia e Educação da Faculdade de Filosofia, Ciências e Letras de Ribeirão Preto, Universidade de São Paulo, Ribeirão Preto.

Oliveira, Z. M. R., Mello, A. M., Vitória, T. \& Rossetti Ferreira, M. C. (1995). Creches: Crianças, faz de conta \& cia. Petrópolis: Vozes.

Oliveira, M. A., Furtado, R. A., Souza, T. N. \& Campos-deCarvalho, M. I. (2003). Avaliação de ambientes educacionais infantis. Paidéia - Cadernos de Psicologia e Educação, 13 (25), 41-58.

Pasquali, L. (1996). Medida psicométrica. Em L. Pasquali (Ed.), Teoria e métodos de medida em ciências do comportamento (pp. 73-115). Brasília: Inep.

Prescott, E. (1987). The environment as organizer of intent in child-care settings. Em C. S. Weinstein \& T. G. David (Eds.), Spaces for children - The built environment and child development (pp. 73-88). New York: Plenum.

Souza, T. N. de (2003). Análise da adequabilidade da Infant/Toddler Environment Rating Scale para avaliar ambientes de creches de Ribeirão Preto. Dissertação de Mestrado, Programa de Pós-Graduação em Psicologia e Educação da Universidade de São Paulo, Ribeirão Preto.

Souza, T. N. de (2003b). A qualidade na educação infantil em questão: Análise de princípios em documentos brasileiros $e$ estrangeiros. Projeto de doutorado - Programa de Pós- 
graduação do Departamento de Psicologia e Educação da Faculdade de Filosofia, Ciências e Letras de Ribeirão Preto, Universidade de São Paulo, Ribeirão Preto.

White, R. \& Stoecklin, V. (1998, March/April). Children's outdoor play and learning environments: Returning to nature. Early Childhood News.

Weick, K. E. (1968). Systematic observational methods. In L. Gardner \& A. Elliot (Eds.), Handbook of social psychology (Vol. II, pp. 357-451). Massachusetts: Wesley.
Weiner, I. B. (1991). Editor's note: Interscorer agreement in Rorschach research. Journal of Personality Assessment, 56, 1.

Recebido em 23/06/2004 Aceito em 30/01/2005

Endereço para correspondência: Mara Campos-de-Carvalho. Depto. de Psicologia e Educação, Faculdade de Filosofia, Ciências e Letras de Ribeirão Preto-USP, Av. dos Bandeirantes, 3.900, CEP 14.040-901, Ribeirão PretoSP.E.mail: mara@ffclrp.usp.br 